\title{
O lugar das juventudes nas produções científicas da Estratégia Saúde da Família: uma revisão sistemática de literatura
}

The place of youth in the scientific productions of the Family Health Strategy: a systematic literature review

\author{
LUIS FERNANDO DE SOUZA BENÍCIO (1) 1 \\ Jõ̃o PAUlo PEREIRA BARRos (1) 1 \\ JAMES FERREIRA MOURA JUNIOR (1 \\ ${ }^{1}$ Universidade Federal do Ceará, Fortaleza, CE, Brasil.
}

RESUMO - As juventudes têm se configurado, nos últimos anos, como um campo fértil de discussão, produção e intervenção em diversas áreas. Ao mesmo tempo em que despertam interesse crescente nos debates públicos, nas intervenções institucionais e nas investigações acadêmicas, observa-se que há um campo de disputas em torno desse segmento. Nesse contexto de maior visibilidade e dizibilidade de problemáticas relativas a essa categoria social no cenário contemporâneo, buscaremos analisar a forma como a categoria juventude tem sido tratada nas produções sobre Estratégia de Saúde da Família (ESF) a partir de uma revisão sistemática de literatura. A revisão se operacionalizou por meio da Biblioteca Virtual em Saúde Brasil (BVS Brasil), devido à sua proposta de reunir bases de dados da área da saúde, possibilitando visibilidade e abrangência das temáticas investigadas. Buscou-se, por meio dessa revisão, desenhar um diagrama das tramas de saber-poder em torno das juventudes no campo da saúde.

Palavras-chave: Juventudes. Estratégia Saúde da Família. Políticas públicas.

ABSTRACT - In recent years, youths have been configured as a fertile field of discussion, production, and intervention in several areas. At the same time that there is a growing interest in public debates, institutional interventions, and academic investigations, it is observed that there is a field of disputes around this segment. In this context of greater visibility and readability of issues related to this social category in the contemporary scenario, we will seek to analyze how youth has been treated in the productions on Family Health Strategy from a systematic literature review. The review was operationalized through the Virtual Health Library Brazil (VHL Brazil), due to its proposal to gather several databases of the health area, making possible the visibility and comprehensiveness of the researched topics. The purpose of this review was to draw a diagram of the knowledge-power plots around the youths in the fields of health.

Keywords: Youth. Family Health Strategy. Public policy. 


\section{Introdução}

A

s juventudes têm se configurado como um campo fértil de discussão, produção e intervenção em diversas áreas, incitando práticas no âmbito das ações governamentais e não governamentais. Exemplo disso, pensando com Paiva e Oliveira (2015), é o novo desenho institucional no âmbito das políticas públicas, a partir de 2004, por meio do desenvolvimento de ações voltadas para o público jovem, fruto de um processo de construção participativa dos movimentos sociais e do governo. Por intermédio desse marco, as autoras citam: a Conferência Nacional de Juventude; o grupo interministerial ligado à Secretaria Geral da Presidência da República; a sanção do Estatuto da Juventude, o qual dispõe sobre direitos dos jovens de 15 a 29 anos, bem como sobre princípios e diretrizes para as políticas públicas de juventude; o Estatuto da Criança e do Adolescente (ECA), de 1990, que continua se aplicando aos jovens de 15 a 18 anos e, por fim, o encaminhamento de projeto de lei que disciplina o Plano Nacional da Juventude.

Ao mesmo tempo em que as juventudes despertam interesse crescente nos debates públicos, nas intervenções institucionais e nas investigações acadêmicas, observa-se que há um campo de disputas em torno desta categoria, ora tida como sujeito de direito, ora como problema. Diógenes e Sá (2011), ao pensarem os atravessamentos em torno do conceito de juventude nos séculos XX e XXI, apontam duas formas elaboradas para conceber as juventudes. A primeira toma as juventudes como um oráculo, investindo no próprio segmento juvenil para tentar um entendimento que ajudaria na produção de políticas públicas. A segunda toma a juventude como enigma, ressaltando certa dificuldade de trazer à tona o entendimento desse segmento. Nesse caso, a condição juvenil seria uma espécie de vitrine das tensões sociais.

Coimbra e Nascimento (2008) afirmam que, na sociedade capitalística, o jovem é construído a partir de uma perspectiva desenvolvimentista que o coloca como um ser em construção, cujos comportamentos são produtos de mudanças físicas e psíquicas. Assim, determinadas qualidades e defeitos, como impulsividade, rebeldia, agressividade, alegria, são tomadas como inerentes a essa fase da vida. Ao lado dessas caracterizações universais e homogeneizantes, que são discutidas pelas autoras, no que se refere aos jovens pobres dentro das várias juventudes, são adicionadas a violência e a criminalidade, o que produz a noção de "juventude perigosa".

Ou seja, ao mesmo tempo em que certas juventudes são vistas como em formação, outras, notadamente, são olhadas e produzidas como expressão do perigo por meio da criminalização. Isso ocorre porque há um processo perverso de perpetuação do racismo e estigmatização da pobreza. As pessoas em situação de pobreza, em sua maioria negras, são reconhecidas como as únicas responsáveis pela sua situação (MOURA JR; XIMENES; SARRIERA, 2014). Há também um processo de naturalização da pobreza, (ACCORSSI; SCARPARO; GUARESCHI, 2012), no qual pobres são reconhecidos como sintagmas da violência e das mazelas socais (MOURA JR; XIMENES, 2016).

Uma visibilidade perversa se dá de modo ainda mais intenso quando esses processos se vinculam à juventude. No Brasil, durante o século XX, começaram a surgir práticas que caracterizam o jovem pobre como perigoso, criminoso e não humano. Tais práticas podem ser observadas, por exemplo, no aumento dos extermínios contra as juventudes negras e pobres, dentre outras práticas de violência contra esse segmento. Percebe-se, assim, que, em meio à produção de juventudes desiguais, tem-se produzido práticas higienistas, tutelares e normativas (COIMBRA; NASCIMENTO, 2005).

Nesse contexto de maior destaque às problemáticas relativas a essa categoria social, temos assistido tanto ao fortalecimento de discursos reacionários marcados pela desqualificação da questão dos direitos humanos, quanto à disseminação de respostas reducionistas a desafios envolvendo os diversos segmentos juvenis. Alguns exemplos desse trato conservador são: o recrudescimento da criminalização e do encarceramento de determinadas juventudes; a medicalização e judicialização das condutas juvenis; o controle dos corpos por meio do dispositivo da sexualidade espraiado em diversos campos institucionais e veículos midiáticos; e a "guerra às drogas" como estratégia repressiva para fazer frente ao uso de substâncias psicoativas por parte de jovens. Temos aí um perverso jogo entre visibilidade e invisibilidade. Por um lado, invisibiliza-se juventudes negras e pobres, habitantes em sua maioria das margens urbanas, em sua condição de sujeitos de direito e alvos de históricas desigualdades. Por outro lado, hipervisibiliza-se tais 
segmentos juvenis, pondo-os na ordem dos discursos e na agenda legislativa e governamental, atribuindoIhes a condição de algozes da violência. O efeito desses regimes de (in)visibilidade são os silenciamentos e as sujeições de diversas experiências juvenis, por meio de tecnologias cada vez mais sofisticadas de controle e governamentalização da vida, sob um prisma trabalhado pelos estudos de Michel Foucault (2008).

Assim, percebe-se que o campo da Saúde Coletiva é uma das arenas em que essa disputa se dá, pois esses processos de estigmatização e controle da juventude ocorrem de maneira mais intensa nesse espaço de produção de conhecimento e controle de modos de vida. Lyra e Sobrinho (2011) apontam que pode ocorrer um processo de invisibilidade estrutural da juventude no campo das políticas públicas de saúde. Trata-se de provocações necessárias para pensar o lugar de jovens nas políticas de saúde, em especial na Atenção Primária em Saúde (APS). Os autores apontam que, a partir dos planos contidos nas diretrizes das políticas de saúde, o processo de descentralização dos serviços e ações fez com que a saúde de segmentos infantojuvenis, abordada em programas anteriores, fosse redirecionada justamente à APS a partir de 1994, com o Programa Saúde da Família (PSF) e o Programa de Agentes Comunitários de Saúde (PACS).

Assim, diante desse campo de problematização sobre os tratos das juventudes na sociedade contemporânea e, especialmente, no âmbito das políticas públicas, interessa-nos analisar a forma como a juventude tem sido tratada nas produções sobre Estratégia de Saúde da Família (ESF) a partir de uma revisão sistemática de literatura.

\section{$1 \quad$ Método}

Para a operacionalização desta pesquisa, foi escolhida a estratégia de revisão sistemática de literatura. De acordo com Zoltowski et al. (2014), esse procedimento metodológico traz qualidade ao processo de análise das temáticas e literaturas investigadas, devendo ser um processo minucioso e detalhado para fins de validade. A revisão se operacionalizou por meio da Biblioteca Virtual em Saúde Brasil (BVS Brasil), devido à sua proposta de reunir diversas bases de dados da área da saúde, possibilitando visibilidade e abrangência das temáticas investigadas.

A busca de artigos ocorreu no mês de março de 2017. Na ocasião, foram selecionados como descritores da pesquisa no campo assunto: "Estratégia Saúde da Família" OR "Programa Saúde da Família" AND "Juventude" OR "Adolescente". A escolha pela terminologia Estratégia Saúde da Família se justifica pela alteração da proposta Programa Saúde da Família, criado em 1994, para Estratégia Saúde da Família, adotado em 2006, quando foi incorporado como uma estratégia permanente para a efetivação dos princípios da Atenção Primária à Saúde brasileira dentro do Sistema Único de Saúde (BENICIO; BARROS, 2017). Nesse sentido, mantemos como opção o descritor Programa Saúde da Família, pois alguns estudos, embora em um período posterior à sua reformulação, ainda referenciam essa antiga terminologia. No que se refere ao descritor Juventude e Adolescente, argumenta-se por existir um campo de tensão entre essas categorias e, também, porque diversos trabalhos as tomam como sinônimas.

O Quadro 1, que mostra os filtros utilizados para essa investigação, apresentada as etapas da inclusão dos filtros e, também, os resultados obtidos.

Quadro 1 - Filtros utilizados na revisão

\begin{tabular}{|l|c|}
\hline Filtros selecionados & Resultados \\
\hline Só descritores & 11.842 \\
\hline Texto disponível & 6.061 \\
\hline Texto disponível + Bases nacionais e bases especializadas & 1.310 \\
\hline Texto disponível + Bases nacionais e bases especializadas + Brasil & 300 \\
\hline Texto disponível + Bases nacionais e bases especializadas + Brasil + Português & 285 \\
\hline Texto disponível + Bases nacionais e bases especializadas + Brasil + Português + 2012; 2013; 2014; 2015 e 2016 & 144 \\
\hline Texto disponível + Bases nacionais e bases especializadas + Brasil + Português + 2012; 2013; 2014; 2015 e 2016 + Artigo & $\mathbf{1 1 7}$ \\
\hline
\end{tabular}

Fonte: Elaborado pelos autores a partir dos dados da pesquisa. 
Do total de 11.842 publicações encontradas, 117 foram selecionadas. Os critérios de inclusão foram: texto disponível; bases nacionais e bases especializadas, pois, na ocasião, existiam outros textos nas bases internacionais. Porém não seria exequível pela quantidade de textos. O Brasil foi adotado como país de discussão, pois a Estratégia Saúde da Família é uma ação governamental específica do Brasil. Foram selecionados o idioma português e os anos de publicação 2012, 2013, 2014, 2015 e 2016. A justificativa para o recorte temporal foi, novamente, a exequibilidade da análise do material e sua atualidade. No caso, optamos por cinco anos, porque a intenção é analisar a produção de conhecimento mais recente desenvolvida no Brasil.

Para os critérios de exclusão dessa pesquisa, foram considerados 1) textos incompletos; 2) bases internacionais; 3) país/região como assunto (América do Sul; América do Norte; Europa; Ásia; Oceania; África; México; Peru; Colômbia; Chile; Caribe; América Central; Cuba; Argentina; Bolívia; Caribe Inglês; República Dominicana; Haiti e Nicarágua; Porto Rico; Venezuela; Equador; El Salvador; Jamaica; Costa Rica; Dominica; Honduras; Paraguai; Barbados; Guatemala; Panamá; Trindad e Tobago e Uruguai); 4) idiomas diferentes do português; 5) anos de publicação anteriores a 2012; e 6) tipos de documentos: (tese, monografia, documento de projeto, não convencional, recurso na internet, recursos educacionais abertos, congresso e conferência, vídeo, perguntas e respostas, áudio e relato).

Com essa primeira gama de artigos identificados, realizou-se a análise do periódico em que o artigo foi veiculado; a base de origem desse periódico, os métodos utilizados nas pesquisas desenvolvidas presentes nos artigos, a macrorregião brasileira onde foi desenvolvido o artigo, a temática trabalhada na publicação e o público participante. Com essas análises realizadas, dos 117 artigos que restaram, constatamos que 2 se repetiam em mais de uma fonte; portanto, excluímos 1, restando 116 artigos. Entretanto, foi realizado um novo critério de exclusão, pois foi identificado que o público adolescente/jovem não era central na maioria das produções. Dessa maneira, excluímos também artigos empíricos que não tinham os jovens como centrais em suas análises. Com esse novo corte, ao tentar selecionar estudos que abordavam o segmento juventude/ adolescente, obtivemos um quantitativo de 8 artigos, fato que resultou na construção de somente um banco de dados para a análise. Foram eliminados, portanto, 109 artigos.

Sobre o formato de análise dessa revisão, guiou-se por uma atitude cartográfica e nas ressonâncias dos estudos foucaultianos, buscaremos, por meio dessa revisão, desenhar um diagrama das tramas de saber-poder em torno das juventudes nos campos da saúde. Deleuze (1986), ao descrever Foucault como um novo cartógrafo, abordando alguns elementos constituintes de sua atitude genealógica, oferece-nos apontamentos do que seria um diagrama como um modo de análise na pesquisa. O diagrama, nestes escritos, é tomado como um mapa que permite acompanhar um conjunto de relações de forças e processualidades, fugindo dos planos das representações de um mundo preexistente e ao mesmo tempo tentando produzir outras realidades.

Com base na revisão realizada e nesta proposta analítica realizada, faremos duas discussões: a primeira problematizará os resultados mais gerais da revisão, chamando atenção para "a invisibilização das juventudes" na maioria dos trabalhos no primeiro banco de artigos. A segunda estará mais direcionada ao banco de 8 artigos que se relacionam especificamente com o segmento juventude/adolescente.

\section{Resultados e Discussão}

\subsection{O lugar da juventude na produção científica na Estratégia de Saúde da Família}

75\% dos artigos foram publicados na base de dados BDENF - Enfermagem seguidos de 3\% LILACSExpress; 5\% de BBO - Odontologia; 5\% Coleciona SUS; 5\% Index Psicologia - Periódicos técnico-científicos; 2\% HISA - História da saúde; $2 \%$ LILACS; 1\% SESSP - ACVSES; 1\% SESSP - ISPROD e 1\% CidSaúde - cidades saudáveis. Identifica-se um número expressivo de publicações na área de Enfermagem. Isso possibilita pensar a ausência de estudos de outras áreas que poderiam contribuir e incidir sobre esse campo.

O Gráfico 1, que mostra os métodos utilizados nos estudos, aponta que a maioria dos trabalhos é formado por pesquisas qualitativas e de campo. 
Gráfico 1 - Tipo de método utilizado nos artigos

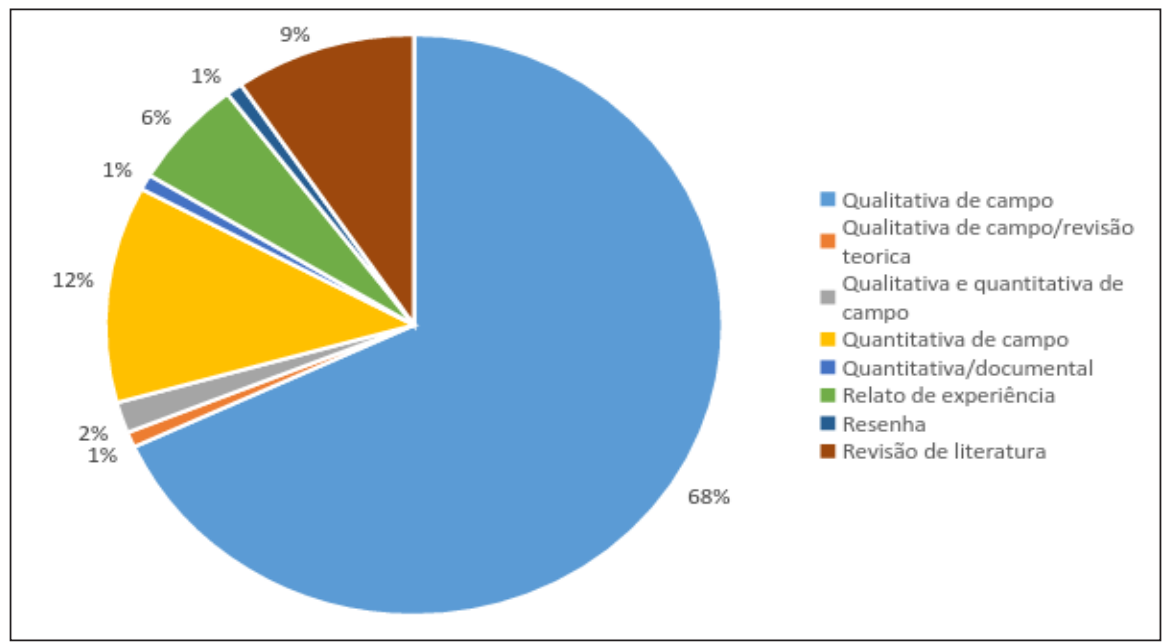

Fonte: Elaborado pelos autores a partir dos dados da pesquisa.

O Quadro 2 apresenta os participantes dos artigos por região do País.

Quadro 2 - Participantes dos artigos por região do País

\begin{tabular}{|c|c|c|c|c|c|}
\hline Região & Participantes & $\mathbf{n}$ & Região & Participantes & $\mathbf{n}$ \\
\hline \multirow[t]{2}{*}{ Norte } & Profissionais da ESF & 19 & \multirow[t]{14}{*}{ Sudeste } & Família & 2 \\
\hline & Pescadores & 1 & & Famílias de crianças/adolescentes & 1 \\
\hline \multirow[t]{13}{*}{ Nordeste } & Agentes comunitários de saúde & 1 & & Usudinds ud tor & \\
\hline & Enfermeiro da ESF & 37 & & Profissionais da ESF & 7 \\
\hline & & & & Médicos & 1 \\
\hline & & & & Enfermeiros da ESF & 1 \\
\hline & Familiares de usuários da ESF & 2 & & Usuários & 7 \\
\hline & Médicos e Enfermeiros da ESF & 1 & & Usuários de saúde mental & 1 \\
\hline & Usuários da ESF & 20 & & Homens & 1 \\
\hline & Adolescente mãe & 1 & & Idosos & 4 \\
\hline & Crianças usuárias & 1 & & Usuários e cuidadores da ESF & 1 \\
\hline & Idosos & 5 & & Usuários da ESF e profissionais da ESF & 1 \\
\hline & Mulheres & 6 & & Usuárias e profissionais da ESF & 1 \\
\hline & Gestantes & 1 & & Enfermeiros e usuários acamados & 1 \\
\hline & Homens & 1 & \multirow[t]{9}{*}{ Sul } & Adolescentes usuários de drogas & 1 \\
\hline \multirow[t]{4}{*}{ Centro-Oeste } & Profissionais & 4 & & Profissionais da ESF & 6 \\
\hline & Enfermeiros & 1 & & Enfermeiro e agente comunitário de & 1 \\
\hline & Agentes comunitários & 1 & & saúde & \\
\hline & Adolescentes, jovens e adultos & 1 & & Médicos da ESF & 1 \\
\hline \multirow{4}{*}{ Sudeste } & Acompanhantes de pacientes & 1 & & Agentes comunitários de saúde & 1 \\
\hline & hospitalizados & 1 & & Usuários da ESF & 2 \\
\hline & Adolescentes & 1 & & Mulheres & 1 \\
\hline & Cuidadores familiares de idosos & 1 & & Usuários de uma UTI & 1 \\
\hline
\end{tabular}

Fonte: Elaborado pelos autores a partir dos dados da pesquisa. 
Assim, sinaliza-se os segmentos/públicos/sujeitos dessas pesquisas, em que o público jovem/ adolescente aparece de forma incipiente quando comparado, por exemplo, ao segmento profissional "enfermeiro". Outro segmento que ganha destaque é o "usuário da ESF" nas pesquisas, mas que não situam o segmento jovem com suas especificidades. Para nos ajudar nessa primeira discussão, o Quadro 3, adiante, indica a invisibilidade desse segmento, notadamente, na região nordeste, cujas temáticas estão direcionadas, prevalentemente, para outros grupos populacionais, como homem adulto e mulher adulta.

Nossa revisão, portanto, reforça e atualiza a seguinte afirmação de Lyra e Sobrinho (2011, p. 112):

No que concerne à saúde dos adolescentes e jovens, historicamente essa população não tem sido foco de atenção das ações de saúde do PSF nem do PACS, que ainda mantêm uma tradição de atuação mais sistemática voltada para o público maternoinfantil.

Lyra e Sobrinho (2011) salientam ainda que, geralmente, a justificativa dada a essa falta de atenção ao público juvenil radica-se em uma suposta maior resistência dos jovens ao adoecimento e, consequentemente, em uma baixa ocorrência de doenças nesse segmento. Vê-se, ainda segundo esses autores, que tais justificativas operam com uma concepção de saúde identificada com mera ausência de doenças, bem como transparece uma visão assistencial e curativa dos serviços, a despeito das reconhecidas mudanças no modelo de atenção à saúde na APS e em outros pontos da atenção, em que se destacam prevenção e promoção. Lyra e Sobrinho (2011) ainda discutem a contradição envolvida na pouca atenção dada ao público juvenil, haja vista que diversos levantamentos têm apontado a alta incidência e o crescimento de mortalidades por causas externas nesse segmento da população, sobretudo decorrentes dos homicídios.

Há um desafio ético-político no âmbito da pesquisa e, consequentemente, sua relevância em promover/investigar práticas locais com destaque para a região do Nordeste. O pouco destaque, na região Nordeste, às práticas com os segmentos juvenis chama-nos atenção, tendo em vista, inclusive, o fenômeno preocupante da nordestinação dos homicídios de jovens. O 9 Anuário Brasileiro de Segurança Pública, de 2015, sinaliza que o Nordeste lidera o ranking de homicídios no País. Em 2014, quatro capitais nordestinas ficaram a frente nos índices: a capital cearense registrou (75,0/100 mil habitantes), Maceió (67, 5/100.000), São Luís $(63,3 / 100.000)$ e Natal $(62,2 / 100.000)$. Acreditamos que, frente a essa problemática intersetorial, cabe à Estratégia Saúde da Família colaborar na tematização e no enfrentamento da problemática dos homicídios na juventude e de suas consequências para as famílias e os amigos de jovens assassinados.

A pouca tematização da juventude na literatura se torna um analisador importante dos tratos contemporâneos das juventudes no Brasil. Ao mesmo tempo em que identificamos pouca discussão sobre a juventude dentro de uma lógica de promoção de saúde, de garantia de direitos e de práticas de cuidado, observa-se que certas juventudes, especialmente as que habitam as margens urbanas, quando debatidas, aparecem muito mais sob uma lógica penal-punitiva por parte das políticas sociais. Atualizam-se, ao mesmo tempo, nos mais diversos segmentos da sociedade, práticas de criminalização, judicialização e patologização, demandando intervenções para determinadas juventudes que possuem endereço, raça e classe social. Exemplo disso são as Propostas de Emendas Constitucionais (PECs) acerca da redução da maioridade penal na Câmara dos Deputados e no Senado Federal, promovendo o aquecimento de discussões sobre responsabilização, controle e repressão da "criminalidade juvenil” (VAVASSORI; TONELI, 2015).

\subsection{Tratos das juventudes nos trabalhos sobre ESF com o público jovem}

Esta seção analisa um total de oito artigos encontrados sobre o público jovem. A maioria possui como temática o processo de atenção produzida em um determinado contexto da ESF, seja direcionada ao adolescente/jovem, seja, ainda, a um segmento profissional no seu processo de cuidado desse segmento. Um dos aspectos que chama atenção é que, dos oito artigos, três têm o Ceará como lócus de produção.

O Quadro 3, que é o segundo banco de dados desse estudo, traz os artigos escolhidos que tratam diretamente da relação da ESF com juventude ou adolescência. 
Quadro 3 - Banco de Dados: Relação ESF com Juventude

\begin{tabular}{|c|c|c|c|c|}
\hline Título & Tema & Região & $\begin{array}{l}\text { Participantes da } \\
\text { pesquisa }\end{array}$ & Autores \\
\hline $\begin{array}{l}\text { Desigualdades sociais e doença } \\
\text { periodontal no estudo SBBrasil } \\
\text { 2010: abordagem multinível }\end{array}$ & $\begin{array}{l}\text { Prevenção de doença } \\
\text { bucal na APS }\end{array}$ & $\begin{array}{l}\text { Distrito } \\
\text { Federal }\end{array}$ & $\begin{array}{l}\text { Adolescentes, jovens e } \\
\text { adultos }\end{array}$ & VETTORE; MARQUES; PERES \\
\hline $\begin{array}{l}\text { Doença crônica da criança: } \\
\text { necessidades familiares e a relação } \\
\text { com a Estratégia Saúde da Família }\end{array}$ & $\begin{array}{l}\text { Acompanhamento de } \\
\text { doença crônica na APS }\end{array}$ & São Paulo & $\begin{array}{l}\text { Famílias de crianças/ } \\
\text { adolescentes usuárias } \\
\text { da ESF }\end{array}$ & $\begin{array}{l}\text { COSTA; SOUSA; WERNET; } \\
\text { DUPAS }\end{array}$ \\
\hline $\begin{array}{l}\text { Gravidez não planejada e fatores } \\
\text { associados à participação em } \\
\text { programa de planejamento familiar }\end{array}$ & $\begin{array}{l}\text { Atenção à saúde da } \\
\text { gestante na APS }\end{array}$ & Minas Gerais & Adolescentes & $\begin{array}{l}\text { EVANGELISTA; BARBIERI; } \\
\text { SILVA }\end{array}$ \\
\hline $\begin{array}{l}\text { Estabelecimento de vínculo com a } \\
\text { mãe adolescente: vislumbrando o } \\
\text { cuidado à criança }\end{array}$ & $\begin{array}{l}\text { Atenção à saúde da mãe } \\
\text { adolescente na APS }\end{array}$ & Ceará & Adolescente mãe & $\begin{array}{l}\text { BRASIL; QUEIROZ; CUNHA; } \\
\text { MAGALHÃES; MAIA }\end{array}$ \\
\hline $\begin{array}{l}\text { Implantação do Programa Saúde } \\
\text { na Escola em Fortaleza-CE: atuação } \\
\text { de equipe da Estratégia Saúde da } \\
\text { Família }\end{array}$ & $\begin{array}{l}\text { Atuação dos profissionais } \\
\text { da ESF }\end{array}$ & Ceará & Profissionais da ESF & $\begin{array}{l}\text { MACHADO; GUBERT; } \\
\text { MEYER; SAMPAIO; DIAS; } \\
\text { ALMEIDA; MORAIS; SILVA; } \\
\text { CAMPOS; CHAGAS; CHAVES }\end{array}$ \\
\hline $\begin{array}{l}\text { Condições de produção do } \\
\text { discurso de enfermeiros na prática } \\
\text { educativa com adolescentes }\end{array}$ & $\begin{array}{l}\text { Prática educativa para } \\
\text { adolescentes na APS }\end{array}$ & Ceará & Enfermeiro da ESF & COELHO \\
\hline $\begin{array}{l}\text { Percepção dos usuários de crack } \\
\text { em relação ao uso e tratamento }\end{array}$ & $\begin{array}{l}\text { Uso de drogas nos } \\
\text { territórios de atuação } \\
\text { da ESF }\end{array}$ & $\begin{array}{l}\text { Rio Grande } \\
\text { do Sul }\end{array}$ & $\begin{array}{l}\text { Adolescentes usuários } \\
\text { de drogas }\end{array}$ & $\begin{array}{l}\text { GABATZ; SCHMIDT; TERRA; } \\
\text { PADOIN; SILVA; LACCHINI }\end{array}$ \\
\hline $\begin{array}{l}\text { Desafios nas ações de atenção } \\
\text { primária: estudo sobre a instalação } \\
\text { de programa de visitas domiciliares } \\
\text { para mães adolescentes }\end{array}$ & $\begin{array}{l}\text { Atenção à saúde da mãe } \\
\text { adolescente na APS }\end{array}$ & São Paulo & $\begin{array}{l}\text { Usuárias e profissionais } \\
\text { da ESF }\end{array}$ & COIN-CARVALHO; ESPOSITO \\
\hline
\end{tabular}

Fonte: Elaborado pelos autores a partir dos dados da pesquisa.

Os temas majoritariamente abordados referem-se a processos de atenção na ESF por parte dos profissionais. A partir dos textos analisados, sobressai a abordagem das juventudes como problema no âmbito da ESF, demandando, por sua vez, práticas preventivas. Isso permite tornar atuais as reflexões de Abramo (1997) sobre o trato social da juventude no Brasil, pois essa segue a se apresentar na cena pública, sobretudo, como "problema social". Para Abramo (1997), prevalecem duas formas de tematizar socialmente a questão da juventude: no que se refere a produtos produzidos para esse público, como música, moda, esporte, lazer etc., os temas são cultura e comportamento; em outra perspectiva, quando os jovens são apresentados aos adultos, por meio de noticiários, jornais etc., os temas mais comuns são relacionados "a problemas sociais" (violência, crime, exploração sexual, problemas com drogas etc.)

Todos os artigos analisados nesta seção referem-se ao segmento juvenil pelo termo "adolescente/ es". Permitindo-nos ficar atentos às noções de adolescência que atravessam determinadas práticas em saúde, em especial, no/do cotidiano da Estratégia Saúde da Família, especialmente por serem perspectivas que, segundo Coimbra, Bocco e Nascimento (2005), tendem a homogeneizar, padronizar e naturalizar esse segmento. Para ilustrar tal problematização, trazemos alguns recortes que corroboram acerca do uso indiscriminado e generalizado do termo, atrelado, em grande parte, a uma perspectiva essencialmente desenvolvimentista e a-histórica de adolescência: "Durante as experiências vivenciadas nas práticas de saúde da criança, observou-se que a mãe adolescente tem necessidades a mais em relação a uma mãe com maior idade em face da simultaneidade de ocorrências em sua vida" (BRASIL et al., 2015, p. 4602). Esse trecho, retirado do estudo "estabelecimento de vínculo com a mãe adolescente: vislumbrando o cuidado à criança", faz referência à existência de um aspecto de turbulência na sua condição de adolescente e, assim, a maternidade sofria interferências quando comparada com a fase adulta. Posteriormente, no trabalho 
"Implantação do Programa Saúde na Escola em Fortaleza, CE: atuação de equipe da Estratégia Saúde da Família", ao desenvolverem um trabalho de educação em saúde nas escolas por meio do contato com o público "adolescente", os autores afirmam que tais atividades poderiam contribuir para a transformação de determinados comportamentos dos adolescentes tidos como não saudáveis e, logo, atrelado a uma perspectiva mais individualizante de tais desafios:

Em um trabalho direcionado aos adolescentes de uma escola pública realizado na cidade de Manacapuru - Amazonas, as atividades educativas mostram-se essenciais à reflexão e sensibilização de comportamentos saudáveis pela clientela participante [...] (SANTIAGO et al., 2012, p. 1028).

Outro trecho, que foi encontrado no estudo "Condições de produção do discurso de enfermeiros na prática educativa com adolescentes", sinaliza a existência de um mundo do ser adolescente que traz consigo muitos desafios para à prática profissional do enfermeiro frente a esse segmento. Além disso, os próprios enfermeiros entrevistados colocam aspectos do comportamento inerentes a um processo existente de adolescer: "percebeu-se, nas enunciações, não apenas o reconhecimento de componentes vivenciais como naturais do processo de adolescer, mas um dizer que sustentava tais traços como fatores dificultadores para a prática do profissional, em que os saberes poderiam ser desafiados pela dinâmica de mundo do adolescente (COELHO et al., 2015, p. 12).

Tais análises apontam a pertinência da discussão de Coimbra e Nascimento (2015) sobre as necessidades de transvalorar os conceitos de adolescência e, também, de juventude. Isso porque, inicialmente, as autoras revisitam as reflexões de Coimbra, Bocco e Nascimento (2005), que analisaram o conceito de adolescência, localizando-o como uma construção histórica em que se optou pela utilização do conceito para propósitos dominantes de homogeneização/padronização e essencialização, remetendo-se a uma espécie de natureza adolescente.

O questionamento apontado pelas autoras indica que, quando tratado em uma perspectiva desenvolvimentista e a-histórica, o segmento juvenil pode ser objeto de práticas institucionais no interior das políticas públicas que buscam sua normalização social. No caso, na maioria dos artigos analisados, existe certa identidade adolescente que justificaria certos comportamentos inerentes à faixa etária. Ao problematizar o uso generalizado e naturalizado do termo adolescente, Coimbra, Bocco e Nascimento (2005) apostaram no conceito de juventude para subverter essa lógica, entretanto, Coimbra e Nascimento (2015) advertem que a mera substituição de adolescência por juventude não basta para se escapar dos possíveis enquadramentos que tratam certos sujeitos sob um prisma universalizante e identitário nas práticas cotidianas.

A presente revisão sistemática corrobora o ponto de vista de que escapar de categorias essencialistas atuantes nas noções de adolescência e também possíveis quando se pensa na categoria juventude, voltadas à homogeneização e reprodução de modelos de ser "adolescente" ou "jovem" a serem consumidos, torna-se um exercício para os campos das políticas públicas, particularmente as de saúde. Logo, um desafio correlato é atuar na invenção de múltiplas juventudes, de outras políticas e, dessa forma, diferentes formas de cuidar e proteger, resistindo à tutela e ao controle (NASCIMENTO, COIMBRA, 2015).

Após realizar essa discussão sobre como o segmento juvenil é referenciado nos campos da saúde, outros elementos surgiram acerca dos tratos das juventudes associadas às noções de risco e prevenção. Para ilustrar, estudos como: "Gravidez não planejada e fatores associados à participação em programa de planejamento familiar"; "Condições de produção do discurso de enfermeiros na prática educativa com adolescentes" e "Percepção dos usuários de crack em relação ao uso e tratamento", permitem observar o lugar do "adolescente" como categoria associada ao risco e que demanda práticas de prevenção.

O trecho a seguir, do estudo "Condições de produção do discurso de enfermeiros na prática educativa com adolescentes", traz tais noções presentes em algumas práticas de saúde, tendo, primeiramente, a sexualidade como dispositivo que articula disciplina e biopolítica, descrevendo a prática sexual do jovem como um indicativo de risco à sua saúde - discurso de profissionais de saúde: 
Durante a discussão a respeito do capítulo construído no almanaque sobre as práticas educativas de profissionais de saúde direcionadas aos adolescentes, esteve presente a compreensão desse sujeito como ser sexualmente ativo, e tal prática como indicativo de risco. (COELHO et al., 2015, p. 11).

Já em outro artigo, a gravidez de adolescente é colocada generalizadamente como risco à saúde, visto que deve trazer diversas complicações clínicas: Esses dados representam um risco maior para esta população, uma vez que a gravidez na adolescência pode ter desfechos maternos e perinatais como o aumento do risco de partos operatórios, prematuridade, baixo peso ao nascer de recém-nascidos [...] (EVANGELISTA; BARBIERI; SILVA, 2015, p. 2470, tradução nossa).

Por sua vez, outro artigo faz uma associação reducionista do uso de drogas por adolescentes ao aumento da criminalidade - colocando, assim, o uso de substância desse segmento um risco para a sociedade:

Entre as preocupações relacionadas ao tema, incluem-se: os desafios para profissionais de saúde no que se refere à abordagem ao usuário; uso cada vez mais precoce em crianças e adolescentes; dificuldades de tratamento e medidas de prevenção; e, o aumento da criminalidade (GABATZ, 2013, p. 141).

Apesar de abordagens distintas no tratamento das juventudes nos campos da saúde, por meio desse recorte de contexto da ESF, percebem-se aproximações no que tange a um conjunto de práticas instituídas no cotidiano dos profissionais que atuam com esse segmento e os tornam um grupo de risco no campo da saúde. Lemos, Scheinvarz e Nascimento (2014) apontam que, frequentemente, a associação entre juventude/adolescência e risco no campo da saúde pública se constitui uma forma de legitimar práticas de normalização e governo de condutas. Ao analisar o acontecimento "crianças e jovens em riscos", problematizando as condições que produziram o risco na cena política como estratégia de defesa social e de prevenção direcionados a crianças e jovens, as autoras colocam que a visão de grupos de riscos exemplifica a produção de estigma e controle social pautados em uma dimensão moral: "As práticas preventivas vão se ampliando, incidindo sobre virtualidades, dirigidas aos fluxos populacionais que são etiquetados pela categoria "em risco" (LEMOS; SCHEINVARZ; NASCIMENTO, 2014, p. 160).

Acerca das práticas (discursivas e não discursivas) que, no campo da saúde, tentam gerenciar, por meio da prevenção, determinadas populações consideradas como de "risco", Caponi (2009) discute que tais práticas acabam exercendo uma atuação de normalização dos corpos, a fim de torná-los "saudáveis", "eficientes" e "adaptáveis". Inspirada nas ideias de Castel (1987), a autora coloca em análise as noções de prevenção em sua estreita relação com a vigilância e à função de antecipar acontecimentos.

As atuais políticas de saúde, para Caponi (2009), parecem se respaldar nessas noções de "periculosidade" e "risco". Os grupos que são acometidos por riscos e, assim, tornam-se grupos de riscos na sua grande maioria, são populações "marginais", historicamente marcadas por desigualdades sociais e violações de direitos. Legitima-se, ao longo da história, um conjunto de intervenções sanitárias dirigidas a essas populações. Nesse sentido, para mensurar os riscos, e, posteriormente, prevenir doenças, faz-se necessário conhecer os modos de vida dessas pessoas, suas condutas, suas relações etc. Por isso, tem-se investido na família para se aproximar desse tipo de conhecimento (CAPONI, 2009). As condições juvenis e as práticas voltadas a jovens são frequentemente naturalizadas, a exemplo da associação corriqueira entre parcela majoritária da juventude brasileira à noção de "risco", servindo, no mais das vezes, como estratégia de governo das condutas a partir da lógica da sociedade da segurança (LEMOS; SCHEINVAR; NASCIMENTO, 2014).

Coimbra e Nascimento (2005) discutem as condições que possibilitaram a juventude pobre receber, historicamente, etiquetas e concepções no âmbito de campos científicos hegemônicos, como nos campos da medicina e biologia. Tais condições denunciam a construção de certas noções que justificam alguns comportamentos a partir de características tomadas como "imutáveis". Surgem, assim, estereótipos, como o do jovem pobre como perigoso e criminoso. Ao colocar em análise essas características, como parte de uma natureza, as autoras denunciam "práticas que têm associado periculosidade, criminalidade e condição 
de não humanidade à situação da pobreza" (COIMBRA; NASCIMENTO, 2005, p. 338). Além disso, tentam apontar/enfrentar os efeitos dessas práticas, em grande parte, visualizados no aumento do número de homicídios de jovens e o aumento de jovens em um cumprimento de medida de reclusão.

Foucault (1988) nos ajuda a pensar riscos a partir da gestão das populações sob uma lógica da segurança. $\mathrm{O}$ autor desenvolve o conceito de biopoder, fazendo referência a essa tecnologia, articulando, no seu processo de constituição, a tecnologia disciplina, que atuaria por meio da docilização dos corpos - cujo enfoque se daria no corpo individual e, também, biopolítica, que atuaria no corpo população. Para o autor, o poder sobre a morte típico da soberania agora é atualizado pela administração dos corpos e pela gestão calculista da vida, à luz de uma governamentalidade securitária. Observou-se, a partir da idade clássica, o desenvolvimento de diversas disciplinas em instituições, nas práticas políticas e econômicas (problemas de natalidade, longevidade, saúde pública, habitação etc.) sendo, portanto, desenvolvidas técnicas diversas para se obter o controle das populações.

Castel (1987) afirma que o saber médico-psicológico, ainda atual nas "práticas de saúde", coloca-se como uma política de gestão das populações:

desse ponto de vista a função de controle social da medicina mental não teria mais grande coisa a ver com uma coerção exercida diretamente: seria um simples instrumento de gestão das populações, que opera sem modificar por si mesmo as pessoas visadas (CASTELS, 1987, p. 111).

A revisão aqui proposta indica justamente a atualidade dessa forte perspectiva de tematização da juventude pela saúde da família que a assujeita por um conjunto de intervenções normalizadoras e homogeneizantes articuladas ao signo do risco e da prevenção.

Essa noção de prevenção aparece em todos os artigos analisados. Para exemplificar, selecionamos alguns trechos que a colocam como pauta transversalizada na atenção ao segmento juvenil no contexto da ESF. O primeiro trecho refere-se a práticas da odontologia no contexto das equipes de ESF, onde, segundo os autores, é necessário investir em um pacote de atuações preventivas para evitar doenças de natureza periodontal que podem ser contraídas por adolescentes: "A maior oferta e facilidade de acesso de serviços de odontologia básica pode ser um importante aliado na prevenção e promoção da saúde periodontal" (VETTORE; MARQUES; PERES, 2013, p. 38).

Depois, outro artigo aponta como se daria o Programa Saúde na Escola, sendo uma articulação entre os Ministérios da Saúde e da Educação. Essa frente aparece como uma importante estratégia de atuação com o segmento juvenil, vislumbrando, segundo seus objetivos, promover a saúde e a cultura de paz:

O PSE apresenta a necessidade de atendimentos clínicos e psicossociais direcionados às crianças e aos adolescentes escolares. Em seus fundamentos, estão inclusas medidas de promoção, prevenção e assistência em saúde em relação à nutrição, à prevenção, ao uso de drogas, à prevenção à violência (COELHO et al., 2015, p. 12).

Colocam-se também, por meio de outro trecho apresentado, a prevenção e a promoção como perspectivas orientadoras para um conjunto de práticas:

O PSE é resultado de uma parceria entre os Ministérios da Saúde e Educação e tem como objetivos promover a saúde e a cultura da paz, enfatizando a prevenção de agravos à saúde; articular ações do setor da saúde e da educação (SANTIAGO et al., 2012, p. 1027).

Predominantemente, por meio dos recortes, observa-se a existência de práticas que fazem referência à prevenção e à assistência à saúde em relação à nutrição, à prevenção ao uso de drogas, à prevenção à violência, à saúde sexual e reprodutiva etc. Para traçar uma linha de discussão acerca das práticas em saúde, sustentada por perspectivas preventistas. Destacam-se, na sua maioria, práticas de prevenção e sua associação estreita com a segurança. Vicentin (2016), por meio de uma análise sobre o sentido de riscos em tempos de prevenção-segurança, aponta como a lógica preventiva ganha espaço nas práticas em saúde, 
materializando-se por meio da prescrição de estilos de vida saudáveis, medicalização da vida, proibicionismo aos diferentes usos de drogas e, por fim, na produção e gestão do medo. Trata-se, então, de um modo de produção de subjetividade presente em diversos espaços da saúde, incluindo na produção acadêmica que, dessa forma, pode atuar na gestão de desejos e medos em torno de estilos de viver.

Buss (2009) considera distinções entre promoção da saúde e prevenção de doenças. A promoção de saúde teria um enfoque mais amplo e abrangente, interessando-se pela investigação e enfrentamento de macrodeterminantes. A promoção da saúde estaria localizada como uma estratégia social, política e cultural apostando no protagonismo dos indivíduos. No caso da prevenção, como discutimos anteriormente com Caponi (2009), o principal objetivo é evitar a enfermidade; o interesse é pela ausência de doenças. O protagonismo seria dos profissionais, considerando uma dimensão mais técnica dos processos.

Ferreira Neto e Kind (2011), ao realizarem uma discussão teórico-metodológica sobre promoção da saúde inspirada em uma leitura foucaultiana, apresentam-nos que o campo da saúde tem sido modificado, sistematicamente, pelas políticas de promoção da saúde, especialmente no deslocamento da centralidade do protagonismo da assistência médica para uma gestão coletiva do cuidado que se afirma na promoção da saúde. Nesse percurso, segundo os autores, mobiliza-se a sociedade para um cuidado individual com o corpo, construindo, assim, determinantes legitimados pela noção de risco (dimensão mais voltada para a prevenção) e, ainda, na noção de condições de vida (enfoque na promoção).

A partir desses marcos, segundo Carvalho (2004 apud FERREIRA NETO; KIND, 2011), dois posicionamentos oriundos das propostas de políticas de promoção à saúde necessitam ganhar atenção. O primeiro, por meio de um caráter progressista, alinha-se a um projeto de nova promoção da saúde, colocando-se disposto a atualizar os compromissos com o coletivo e os princípios democráticos que marcam a saúde pública.

O segundo, para o qual queremos chamar a atenção, reatualizam a ótica de formações neoliberais, individualistas pautados na regulação e na vigilância. Por ser um campo de disputas, dentro da saúde coletiva, cria-se um campo de forças que atravessam um conjunto de práticas no cotidiano da Atenção Primária brasileira. Por meio das discussões produzidas acerca desses embates, pretendemos, como Ferreira Neto e Kind (2011), trazer à tona a problematização do campo da promoção da saúde presentes nas práticas institucionais que são, consequentemente, práticas sociais voltadas para as juventudes.

Diante desse campo de problematização, interessou-nos, neste estudo, investigar como as juventudes têm sido tematizadas no campo da saúde, especialmente, no campo da Estratégia Saúde da Família, a partir de uma revisão da literatura. Para a discussão dos resultados, analisamos como os segmentos juvenis aparecem como um problema social para o campo da saúde, associados em grande parte ao risco, requerendo, assim, práticas de saúde organizadas, sobretudo, pelos signos da reabilitação e prevenção.

Os dados trazidos ao longo dessa revisão sistemática de literatura permitem considerar a presença de um campo de forças que aponta para perspectivas regulamentadoras e disciplinadoras no trabalho com as juventudes. Pensamos o que seria uma perspectiva disciplinadora com Foucault (1987), sendo uma estratégia de poder que visa constituir corpos dóceis, fabricar indivíduos, majorando as suas forças econômicas e produtivas e minorando as suas forças políticas, por meio da combinação de procedimentos como vigilância, sanção normalizadora e exames. No que se refere a uma perspectiva regulamentadora encontrada nos trabalhos, Foucault (1988), nos livros História da sexualidade 1; Em defesa da sociedade; Segurança, território, população; e, Nascimento da biopolítica, ajuda-nos a pensar tal tecnologia relacionada a um investimento biopolítico no conjunto da população, no caso, das juventudes, visando à gestão de seus modos de vida.

Por meio das linhas de saber-poder-subjetivação que atravessam os estudos da revisão, é possível questionar em que medida estamos falando de controle ou cuidado se tratando de segmentos juventudes. O conceito de biopolítica, pensado por Foucault em História da Sexualidade I (1988), ajuda-nos entender a atualização de dispositivos que incidem no corpo-espécie, no sentido de otimizar os modos de viver e produzir práticas de normalizações, dado a articulação entre a perspectiva preventiva e securitária. Há, assim, nessa produção analisada uma estratégia de subjugação do jovem, que é compreendido como a-histórico, compreendido como uma população homogênea de risco, que necessita ser controlada. 


\section{Considerações finais}

Em nossa análise, considerando o recorte realizado, identificamos uma relativa invisibilização das juventudes no tocante à APS, tendo em vista que as discussões a seu respeito figuram em segundo plano na produção científica sobre ESF. Além disso, as perspectivas de promoção de saúde, adotadas na maioria dos trabalhos, indicam a predominância de abordagens tecnicistas no trabalho na APS. Ressaltamos, então, o desafio de efetivar os princípios da ESF em uma abordagem mais psicossocial e menos ambulatorial. As juventudes, tratadas como "adolescentes", são tomadas, por vezes, como problema social nos trabalhos analisados, pois são referenciadas performatizando comportamentos de risco a sua saúde. Demanda-se, portanto, práticas interventivas que respondam aos "problemas" de gravidez precoce, uso de drogas e aumento da criminalidade, prática sexual arriscada ou/e surgimento de doenças no seu desenvolvimento.

Apontam-se linhas que indicam o uso da perspectiva de prevenção cujos efeitos são a reiteração de processos de tutela de adolescentes associados à noção de risco, cruzando e retroalimentando perspectivas proibicionistas e higienistas, o que despotencializa coproduções de linhas de resistências frente à invisibilização desse segmento ou a sua visibilização perversa como problema social. Chama-nos atenção, também, por meio dessa revisão de literatura, a predominância de discussões sobre adolescência e juventudes e as lógicas operadas com ela (noções desenvolvimentistas que tentam homogeneizar comportamentos-fenômenos pautados nas faixas etárias). Subverter e transvalorar, portanto, essas noções, inventando também outros modos de pensar e fazer políticas públicas torna-se de grande relevância para o campo da saúde, com a ajuda das discussões e das referências apontadas neste estudo.

\section{Referências}

ABRAMO, H. W. Considerações sobre a tematização social da juventude no Brasil. Revista Brasileira de Educação, Rio de Janeiro, v. 5, n. 6, p. 25-36, 1997.

ACCORSSI, A.; SCARPARO, H.; GUARESCHI, P. A naturalização da pobreza: reflexões sobre a formação do pensamento social. Psicologia \& Sociedade, Porto Alegre, v. 24, n. 3, p. 536-546, 2012. https://doi.org/10.1590/S0102-71822012 000300007

BENICIO, L. F.; BARROS, J. P. P. Estratégia Saúde da Família e Violência Urbana: abordagens e práticas sociais em questão. SANARE-Revista de Políticas Públicas, Sobral, CE, v. 16, n. 1, p. 102-112, 2017.

BRASIL, E. G. M. et al. Estabelecimento de vínculo com a mãe adolescente: vislumbrando o cuidado à criança Bond. Revista de Pesquisa: Cuidado é Fundamental Online, Rio de Janeiro, v. 8, n. 3, p. 4601-4608, 2016. https://doi. org/10.9789/2175-5361.2016.v8i3.4601-4608

CAPONI, S. A saúde como abertura ao risco. In: CZERESNIA, D. (org). Promoção da saúde: conceitos, reflexões, tendências. Rio de Janeiro: Editora Fiocruz, 2009. p. 55-77.

CASTEL, R. A gestão dos riscos. Rio de Janeiro: Editora Francisco Alves, 1987.

COELHO, M. M. F. et al. Condições de produção do discurso de enfermeiros na prática educativa com adolescentes Revista Enfermagem UERJ, Rio de Janeiro, v. 23, n. 1, p. 9-14, 2015. https://doi.org/10.12957/reuerj.2015.9618

COIMBRA, C.; BOCCO, F.; NASCIMENTO, M. L. Subvertendo o conceito de adolescência. Arquivos brasileiros de psicologia, Rio de Janeiro, v. 57, n. 1, p. 2-11, 2005.

COIMBRA, C.; NASCIMENTO, M. L. A Produção de crianças e jovens perigosos: a quem interessa. CEDECA, Direitos humanos não tem idade. Rio de janeiro, v. 20, p. 1-11, 2008.

COIMBRA, C.; NASCIMENTO, M. L. Ser jovem, ser pobre é ser perigoso. Jovenes: Revista de Estudios sobre Juventud, Espanha, v. 9, n. 22, p. 338-355, 2005.

DELEUZE, G. Foucault. São Paulo: Editora Brasiliense, 1986. 
DIOGENES, G.; SA, L. Juventude e segurança pública: dissonâncias e ressonâncias. In: PAPA, F.C.; FREITAS, M.V. Juventudes em pauta: políticas públicas no Brasil. São Paulo: Peirópolis, 2011. p. 119.

EVANGELISTA, C. B.; BARBIERI, M.; SILVA, P. L. N. Gravidez não planejada e fatores associados à participação em programa de planejamento familiar. Revista de Pesquisa: Cuidado é Fundamental Online, Rio de Janeiro, p. 2464-2474. 2015.

FERREIRA NETO, J. L; KIND, L. Promoção da saúde: uma discussão teórico-metodológica com base em Foucault. In: FERREIRA NETO, J .L; KIND, L (org). Promoção da saúde: práticas grupais na Estratégia Saúde da Família. São Paulo: HUCITEC; Belo Horizonte: FAPEMING, 2011. p. 23- 53.

FORTALEZA. Secretaria Municipal de Saúde de Fortaleza. Homicídios de crianças e adolescentes de 10 a 19 anos em Fortaleza: análise epidemiológica e espacial 2000-2016. Fortaleza: SMSF, 2016.

FÓRUM BRASILEIRO DE SEGURANÇA PÚBLICA. 9 Anuário Brasileiro de Segurança Pública. [S. I.: s. n.], 2015.

FOUCAULT, M. A arqueologia do saber. Rio de Janeiro: Forense Universitária. 2008.

FOUCAULT, M. A história da sexualidade: a vontade de saber. Rio de Janeiro: Forense Universitária, 1988.

FOUCAULT, M. Vigiar e Punir. Petrópolis: Vozes, 1987.

GABATZ, R. I. B. et al. Percepção dos usuários de crack em relação ao uso e tratamento. Revista Gaúcha de Enfermagem, Porto Alegre, v. 34, n. 1, p. 140-146, 2013. https://doi.org/10.1590/S1983-14472013000100018

LEMOS, F. C. S.; SCHEINVAR, E.; NASCIMENTO, M. L. Uma análise do acontecimento "crianças e jovens em risco". Psicologia \& Sociedade, Porto Alegre, v. 26 n. 1, p. 158-164, 2014. https://doi.org/10.1590/S0102-71822014000100017

LYRA, J.; SOBRINHO, A. Políticas públicas de juventude. In: PAPA, F. C.; FREITAS, M. V. (org.). Juventudes em pauta: políticas públicas no Brasil. São Paulo: Peirópolis, 2011. p. [1-37].

MOURA JR., J. F.; XIMENES, V. M. A identidade social estigmatizada de pobre: uma constituição opressora. Fractais: Revista de Psicologia, Rio de Janeiro, v. 28, n. 1, p. 76-83, 2016. https://doi.org/10.1590/1984-0292/1051

MOURA JR., J. F.; XIMENES, V. M.; SARRIERA, J. C. A construção opressora da pobreza no Brasil e suas consequências no psiquismo. Quaderns de Psicologia, v.16, n. 2, p. 85-93. 2014. https://doi.org/10.5565/rev/qpsicologia.1174

PAIVA, I. L.; OLIVEIRA, I. F. Juventude, violência e políticas sociais: da criminalização à efetivação de direitos humanos. In: SCISLESKI, A.; GUARESCHI, N. (Org.). Juventude, marginalidade social e direitos humanos: da psicologia às políticas públicas. Porta Alegre: EDIPUCRS, 2015. p. 41-54.

SANTIAGO, L. M. et al. Implantação do Programa Saúde na escola em Fortaleza-CE: atuação de equipe da Estratégia Saúde da Família. Revista Brasileira de Enfermagem, Brasília, DF, v. 65, n. 6, p. 1026-1029, dez. 2012. https://doi.org/10.1590/ S0034-71672012000600020

VAVASSORI, M. B.; TONELI, M. J. F. Constitutional Amendments to Lower the Age of Criminal Responsibility: Brazilian Youth on a Knife Edge? Psicologia: Ciência e Profissão, Brasília, DF, v. 35, n. 4, p. 1188-1205, 2015. https://doi.org/10.1590/19823703001732014

VETTORE, M. V.; MARQUES, R. A. A.; PERES, M. A. Desigualdades sociais e doença periodontal no estudo SBBrasil 2010: abordagem multinível. Revista de Saúde Pública, São Paulo, v. 47, n. 3, p. 29-39, 2013.

VICENTIN, M. C. Sobre como inverter o sentido de riscos em tempos de prevenção-segurança: a saúde como intercessor. In: KASTRUP, V; MACHADO, A. M. (org). Movimentos micropolíticos em saúde: formação e reabilitação. Curitiba: CRV, 2016. p. 11-18. https://doi.org/10.1590/S0034-8910.2013047004422

ZOLTOWSKI, A. P. C. et al. Qualidade metodológica das revisões sistemáticas em periódicos de psicologia brasileiros. Psicologia: teoria e Pesquisa, v. 30, n. 1, p. 97-104, 2014. https://doi.org/10.1590/S0102-37722014000100012 
Correspondência para:

Luis Fernando de Souza Benício

Universidade Federal do Ceará

Centro de Humanidades - Departamento de Psicologia

Avenida da Universidade, 2801/2802 - Benfica

60020-181, Fortaleza, CE, Brasil

\section{Autores:}

LUIS FERNANDO de SOUZA BEnícIo

Mestre e Doutorando em Psicologia pelo Programa de Pós-Graduação em Psicologia da

Universidade Federal do Ceará (PPGP/UFC), Fortaleza, CE, Brasil.

Orcid: https://orcid.org/0000-0002-0765-2568

E-mail: luisf.benicio@gmail.com

\section{JoÃo Paulo PEREIRA BarRos}

Doutor em Educação pelo Programa de Pós-Graduação em Educação da Universidade Federal do Ceará (PPGE/UFC), Fortaleza, CE, Brasil. Professor e Coordenador do Programa de Pós-Graduação em Psicologia da Universidade do Ceará (PPGP/UFC), Fortaleza, CE, Brasil.

Orcid: https://orcid.org/0000-0001-7680-576X

E-mail: joaopaulobarros07@gmail.com

Endereço: Universidade Federal do Ceará - Centro de Humanidades - Departamento de Psicologia

Avenida da Universidade, 2801/2802 - Benfica - 60020-181, Fortaleza, CE, Brasil

JAMES FERREIRA MOURA JUNIOR

Doutor em Psicologia pelo Programa de Pós-Graduação em Psicologia da Universidade Federal do Rio Grande do Sul (PPGP/UFRGS),

Professor do Programa de Pós-Graduação em Psicologia da Universidade Federal do Ceará (PPGP/UFC), Fortaleza, CE, Brasil.

Orcid: https://orcid.org/0000-0003-0595-5861

E-mail: jamesferreirajr@gmail.com

Endereço: Universidade da Integração Internacional da Lusofonia Afro-Brasileira - Instituto de Humanidades e Letras

Avenida da Abolição, 3 - Centro - 62790-000, Redenção, CE, Brasil 